\title{
Effects of the Electrode Modification Conditions on the Performance of Three-state Electrochromic Devices via Spin- coating
}

\author{
L. Wu, L.X. Fei, D.J. Yang, F. Wu, X.L. Peng, Y.L. Zhu, S.P. Song, Y. Xiang ${ }^{*}$ \\ School of Energy Science and Engineering, University of Electronic Science and Technology of \\ China, 2006 Xiyuan Ave, West High-Tech Zone, Chengdu, Sichuan 611731, China. \\ *E-mail: xyg@uestc.edu.cn
}

doi: $10.20964 / 2017.08 .80$

Received: 24 May 2017 / Accepted: 17 Jube 2017 / Published: 12 July 2017

\begin{abstract}
Electrodeposition-based electrochromic devices capture numerous attentions due to their simple sandwich-type structure, facile and low-cost fabrication, and promising application. Herein, titanium dioxide $\left(\mathrm{TiO}_{2}\right)$ nanoparticles were modified onto fluorine doped tin oxide (FTO) electrode via spin-coating technique with different rotation speed and precursor solution concentration, followed by sandwiching a suitable amount of gel electrolyte between the modified FTO electrode and a flat FTO electrode to fabricate the electrodeposition-based electrochromic device with reversible three-state optical transformation (transparent, mirror and black). A systematic study of correlation between electrode modification condition and morphological features of $\mathrm{TiO}_{2}$ thin films, as well as the performance of electrochromic devices, i.e. optical contrast, switching time, and cycling stability, were investigated. Optimized performances of three-stated electrochromic device could be obtained by properly manipulating the electrode modification conditions. The results in this study will provide valuable guidance for rational design of electrochromic device with satisfactory performance.
\end{abstract}

Keywords: Electrochromic; Spin-coating; Rotation Speed; Precursor Solution Concentration; Morphological Features; Electrochromic Properties

\section{$\underline{\text { FULL TEXT }}$}

(C) 2017 The Authors. Published by ESG (www.electrochemsci.org). This article is an open access article distributed under the terms and conditions of the Creative Commons Attribution license (http://creativecommons.org/licenses/by/4.0/). 